Original article

\title{
Prevalence of late-life depression and gap in mental health service use across European regions
}

\author{
Katerina Horackova ${ }^{\mathrm{a}}$, Miloslav Kopecek ${ }^{\mathrm{a}, \mathrm{b}}$, Vendula Machư ${ }^{\mathrm{b}, \mathrm{c}}$, Anna Kagstrom $^{\mathrm{b}}$, \\ Dag Aarsland ${ }^{\mathrm{d}}$, Lucie Bankovska Motlova ${ }^{\mathrm{a}, \mathrm{b}}$, Pavla Cermakova ${ }^{\mathrm{a}, \mathrm{b}, *}$ \\ a Third Faculty of Medicine, Charles University Prague, Czech Republic \\ ${ }^{\mathrm{b}}$ National Institute of Mental Health, Klecany, Czech Republic \\ ${ }^{\mathrm{c}}$ Faculty of Science, Charles University Prague, Czech Republic \\ d Department of Old Age Psychiatry, Institute of Psychiatry, Psychology and Neuroscience, King's College, London, UK
}

\section{A R T I C L E I N F O}

\section{Article history:}

Received 18 October 2018

Received in revised form 4 December 2018

Accepted 8 December 2018

Available online 15 January 2019

\section{Keywords:}

Depression

Old age

Epidemiology

Europe

\begin{abstract}
A B S T R A C T
Background We aimed to determine the prevalence and gap in use of mental health services for late-life depression in four European regions (Western Europe, Scandinavia, Southern Europe and Central and Eastern Europe) and explore socio-demographic, social and health-related factors associated with it.

Methods We conducted a cross-sectional study based on data from the Survey on Health, Ageing and Retirement in Europe. Participants were a population-based sample of 28796 persons (53\% women, mean age 74 years old) residing in Europe. Mental health service use was estimated using information about the diagnosis or treatment for depression.

Results The prevalence of late-life depression was 29\% in the whole sample and was highest in Southern Europe (35\%), followed by Central and Eastern Europe (32\%), Western Europe (26\%) and lowest in Scandinavia (17\%). Factors that had the strongest association with depression were total number of chronic diseases, pain, limitations in instrumental activities of daily living, grip strength and cognitive impairment. The gap in mental health service use was $79 \%$.

Conclusions We suggest that interventions to decrease the burden of late-life depression should be targeted at individuals that are affected by chronic somatic comorbidities and are limited in mental and physical functioning. Promotion of help-seeking of older adults, de-stigmatization of mental illness and education of general practitioners could help decrease the gap in mental health service utilization.
\end{abstract}

(C) 2018 Elsevier Masson SAS. All rights reserved.

\section{Introduction}

Given the ageing population, mental health of older adults is becoming a public health concern. It is estimated that one third of individuals older than 65 years have experienced a mental illness during the past year [1]. Depression is a leading cause of disability of older adults and is associated with cognitive and physical decline, poor quality of life and excess mortality [2]. Previous studies indicate that the prevalence of late-life depression (LLD) largely varies across Europe [1,3-9]. Some studies suggested a higher burden of LLD in Southern and Central Eastern Europe (CEE), when compared to Western European and Scandinavian countries [3-5,7,9]. However, the reasons for this large variation are not clear and the region of CEE has been well represented only in a few studies [3,5,7].

\footnotetext{
* Corresponding author at: National Institute of Mental Health, Topolova 748, 250 67, Klecany, Czech Republic.

E-mail address: Pavla.Cermakova@nudz.cz (P. Cermakova).
}

LLD is a multifactorial disorder influenced by genes, environment and gene-environmental interactions, suggesting that it is to some extent preventable [2]. Risk factors are substantially different for LLD when compared to depression in younger individuals [10-12]. For example, socioeconomic conditions have been suggested as predictors of depression especially in younger cohorts, while in older participants, depression may mostly be influenced by frequency of social meetings, marital status and contact with children and grandchildren [7,13]. In addition, LLD is in a strong, reciprocal relationship with many chronic diseases, such as cancer, cardiovascular diseases (CVD) or cognitive impairment, which in turn may lead to pain, disability as well as higher risk of death [14-16]. Unhealthy behaviours such as smoking, alcohol abuse and physical inactivity may be important mediators in these associations [17].

There is robust evidence demonstrating that although depression in older adults may be more difficult to treat than in younger individuals, comprehensive treatment schemes combining psychosocial, medical and pharmacological approaches are helpful [18]. However, there is a substantial gap between older adults 
experiencing symptoms of LLD and those who are detected by mental health services (MHS) and are then treated [19]. Increasing detection of LLD in primary care, which is the most frequent point of contact between older adults and health care system, is a crucial strategy to reduce the burden of depression, improve the quality of life and prevent suicides in old age [20].

Reasons for under-detection of LLD are multi-faceted, and include patients, physicians as well as societal factors [21-23]. First, older adults are less likely than younger adults to recognize signs of depression and to perceive a need for using MHS to seek treatment [22]. Second, symptoms of LLD differ from those observed in younger populations and diagnosis of LLD by physicians is complicated by co-existent cognitive and somatic diseases [21]. Specifically, fatigue, cognitive impairment, apathy and other signs of LLD may be falsely perceived as a result of chronic somatic illness and not as a separate mental illness. Third, societal stigma towards mental disorders may prevent acknowledgment of the illness and be a barrier to MHS use [23].

European countries differ widely in the public burden of unhealthy behaviours, opportunities for older adults, health care policies concerning the treatment of depression as well as attitudes towards mental illness [3-9]. Previous studies on the burden of LLD across Europe have been conducted either as social surveys, studies focusing on somatic comorbidities or differences on the macro-level in mental health care system, but, to the best of our knowledge, no study has taken all relevant factors into account. Our objective was to (1) determine the prevalence of LLD in 4 European regions: Western Europe, Scandinavia, Southern Europe and CEE; (2) determine which socio-demographic, social and health-related factors are associated with LLD and (3) explore the gap in MHS use for LLD and factors that relate to it.

\section{Methods}

\subsection{Source of data}

We performed a cross-sectional study based on data from the Survey on Health, Ageing and Retirement in Europe (SHARE). SHARE is a multidisciplinary and cross-national study that aims to understand the trajectories of health, social network and economic conditions of the aging population in 27 European countries and Israel [24]. The target population were individuals aged 50 years and more, speaking the official language of the country and not living abroad or in an institution during the duration of the field work. If they had a partner, their partners were also eligible to be included irrespective of age. The collection of data was performed by computer-assisted personal interviewing(CAPI). The first wave of interviews was conducted in 2004 and was followed by 5 subsequent waves in approximately 2 -year intervals, with the $6^{\text {th }}$ wave being completed in 2015 .

The sampling was based on probability selection, but the sampling frames were allowed to vary between countries. For example, stratified simple random sampling from national population registers was chosen in Denmark and Sweden, while multi-stage sampling using regional or local population registers was performed in Germany, Italy and Spain. Single or multi-stage sampling using telephone directories followed by screening in the field was used in Austria, Greece and Switzerland. New individuals were enrolled as refreshment samples in order to compensate for the drop out of participants. Methodological details about the study are available on http://www.share-project.org/.

\subsection{Standard protocols, approvals and participants' consent}

This paper uses data from the $6^{\text {th }}$ wave of SHARE, see elsewhere for details [24] (DOI: 10.6103/SHARE.w6.600). SHARE has been repeatedly reviewed and approved by the Ethics Committee of the
University of Mannheim. All participants provided written consent. Their data were pseudo-anonymized and they have been informed about the storage and use of the data and their right to withdraw consent. The present analysis was approved by the Ethics Committee of the National Institute of Mental Health, Czech Republic.

\subsection{Assessment of depression}

Depression was assessed using EURO-D scale, which was administered by centrally trained interviewers as a part of CAPI. The EURO-D scale was originally developed to compare symptoms of LLD across 11 European countries in the EURODEP Concerted Action Programme [25] and has been used in many epidemiological studies. The 12 EURO-D items (depressed mood, pessimism, wishing death, guilt, sleep, interest, irritability, appetite, fatigue, concentration, enjoyment and tearfulness) are scored 0 (symptom not present) or 1 (symptom present), generating an ordinal scale with a maximum score of 12 . Higher scores are suggestive of a greater severity of depressive symptoms.

Even though it could be more accurate to assess degrees of appearance of depressive symptoms over time, as used in previous studies $[1,26]$, rather than the presence of symptoms, we utilize this ordinal scale in the present study in order to capture current symptomatology. EURO-D scale is not a diagnostic instrument, however, previous studies suggest that reaching 4 or more points on this scale indicate the presence of major depression [25]. Here, we created a binary variable where 4 or more points stood for LLD (coded as 1 , relative to $0=$ no depression).

\subsection{Gap in use of MHS}

The gap in MHS use has been widely defined as a proportion of persons that do not utilize MHS out of persons that have a diagnosable mental disorder [27]. In this present study, we operationalize utilization of MHS by combining two pieces of information: self-reported diagnosis (when the participants positively answered a question whether they have been told by a doctor that they have affective or emotional disorders) and selfreported medication (when the participants answered positively to a question whether they are using drugs against depression or anxiety). Individuals that answer positively to either item are classified as having utilized MHS. Thus, the gap in MHS use is represented by individuals that have prevalent depression but have received neither a diagnosis nor treatment.

\subsection{Covariates}

We identified covariates based on literature as sociodemographic and social characteristics, comorbidities and general health-related factors that may be associated with LLD and the MHS use. Sociodemographic characteristics were age, gender, years of education, type of residence, immigration, current job situation and household income. Social characteristics included family status, number of children, number of grandchildren and number of persons with whom the person has daily contact. Comorbidities included CVD, cancer, cognitive impairment, number of chronic diseases and whether the participant is troubled by pain. General health-related factors contained information about physical activity, body mass index (BMI), alcohol use, smoking, instrumental activities of daily living (IADL), grip strength and computer use. Detailed definition of covariates is provided in the Supplement.

\subsection{Study sample}

We focused on older adults, defined as persons aged 65 years or older, as previously used [28], and studied individuals who 
participated in the 6th wave of SHARE in 2015. We excluded participants from Israel $(n=1357)$ in order to focus only on European regions. Further, we excluded individuals who had missing data on depressive scores $(n=2408)$, leaving the sample of 36069 (55\% women; mean age 74 years old), from which the prevalence of LLD is derived. Individuals excluded due to missing data on depressive scores were older (median 80 vs. 73; $\mathrm{p}<0.001$ ) and less educated (mean 8 vs. 10 years of education; $p<0.001$ ) compared to the final analytical sample.

For statistical analysis, we additionally excluded individuals that had missing data on covariates ( $n=7$ 273), leaving 28796 participants in the final analytical sample (53\% women; mean age 74 years old). The individuals excluded due to missing data on covariates had a higher frequency of LLD than those included in the analysis (39\% vs. 27\%; p < 0.001 ). Four European regions were represented in the final analytical sample: Western Europe (Austria, Germany, Switzerland, Belgium, France, Luxembourg; $\mathrm{n}=9$ 940), Southern Europe (Spain, Italy, Portugal, Greece; $n=7$ 022), CEE (Czech Republic, Poland, Hungary, Slovenia, Estonia, Croatia; $n=7$ 845) and Scandinavia (Sweden, Denmark; $n=3$ 989). A flowchart is presented in Supplemental Figure S1.

\subsection{Statistical analysis}

We present the prevalence of LLD and the gap in MHS use in the whole sample as well as stratified by region. First, we report the crude number and second, we use calibrated cross-sectional sampling weights based on the procedure by Deville and Särndal
[29]. Weighting enables us to reduce the potential selection bias generated by participants' non-response at baseline and refreshment samples of each wave and sample attrition. The weights were calculated for 8 age-groups, gender and region according to the regional demographic statistics given by Eurostat.

To compare persons with and without LLD, we used an independent sample $t$-test for continuous variables with normal distribution, Mann-Whitney test for continuous variables with skewed distribution and $\chi^{2}$ test for binary variables. We considered covariates that were statistically significant in univariate analysis at the level of $\mathrm{p}<0.001$ (given the large sample size and multiple predictors tested) to be included in multivariable analysis. We then applied binary logistic regression to estimate odds ratio (OR) with 95\% confidence interval (CI) for the association of individual covariates with LLD. The final model included covariates that were significantly associated with the dependent variable or improved the pseudo $\mathrm{R}^{2}$ of the model.

We performed dominance analysis to calculate the relative importance of each covariate in the final models and proportion of variance explained by them [30]. The output from the dominance analysis are standardized weights, which are the general dominance weights from McFadden $\mathrm{R}^{2}$ normed to be out of $100 \%$. Based on these, we selected the 5 most important covariates that explain the highest proportion of the variance of LLD. In the end, we studied individuals classified with LLD and explored factors associated with the MHS use. We performed univariate and multivariable analysis as described above. Analyses were performed using STATA (Version 15.1).

A) PREVALENCE OF LATE-LIFE DEPRESSION

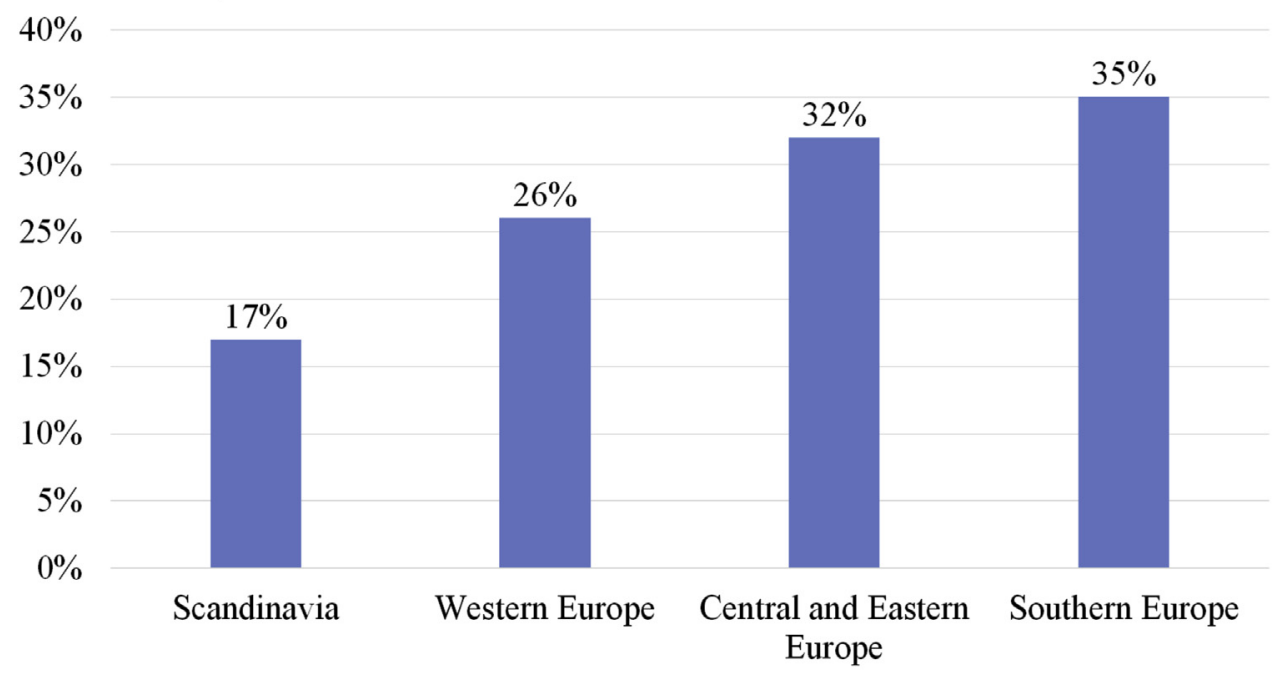

\section{B) GAP IN MENTAL HEALTH SERVICE USE FOR LATE-LIFE DEPRESSION}

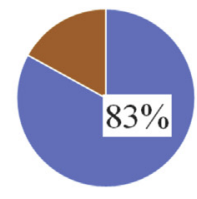

Scandinavia

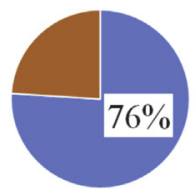

Western Europe

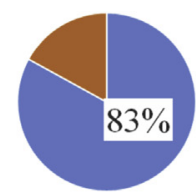

Central and Eastern Europe

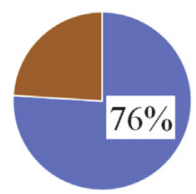

Southern Europe

Fig. 1. Prevalence of late life depression and associated gap in mental health service use in European regions ( $\mathrm{n}=36069$ ). 


\section{Results}

From the 36069 individuals in the sample, 10483 (29\%) were classified with LLD. The prevalence was highest in Southern Europe (35\%), followed by CEE (32\%), Western Europe (26\%) and the lowest in Scandinavia (17\%; $\mathrm{p}<0.001$ from ANOVA; Fig. 1A). Using sampling weights, the prevalence in the whole sample was 33\% and was highest in CEE (42\%), followed by Southern Europe (37\%), Western Europe (29\%) and Scandinavia (18\%).

Individuals classified with LLD were older, had a lower socioeconomic status and had more comorbidities (Table 1 ). In multivariable analysis, the model that best explained the variation in LLD included gender, age, household net income, family status, CVD, cancer, cognitive impairment, total number of chronic diseases, BMI, physical inactivity, IADL, pain, grip strength and computer use (Supplemental Table S1). We observed several differences in analyses stratified by gender and region (Supplemental Tables S1 and S2).

According to dominance analysis (Table 2), the most important factors in the final model were total number of chronic diseases, pain, IADL, grip strength and cognitive impairment, which together explained $73 \%$ of the variance of LLD. When stratified by gender, the same 5 variables were observed to be the most important for women, while for men, physical activity took the $4^{\text {th }}$ rank in the dominance analysis, replacing grip strength. Stratification by region revealed that number of chronic diseases, pain, IADL and grip strength are thefour most important factors in all regions. The $5^{\text {th }}$ rank was taken by gender in Western Europe, cognitive impairment in Southern Europe and CEE and physical inactivity in Scandinavia.

The gap in MHS use was $79 \%$ in the whole sample and was lower in Western and Southern Europe (both 76\%) and higher in Scandinavia and CEE (both 83\%; Fig. 1B). Using sampling weights, the gap in MHS use in the whole sample was also $79 \%$. Service users were younger, more frequently women and had more comorbidities (Table 3). In multivariable analysis, use of MHS was associated with a higher number of chronic diseases, more limitations in IADL, lower age, female gender, cognitive impairment and lower BMI (Table 4). The single most important factor was number of chronic diseases, which explained $67 \%$ of variance of the model. It was the most dominant factor in all regions and for both genders (not presented in tables).

\section{Discussion}

In this population-based cohort study of approximately 30000 individuals, uniquely large and well-characterized nationally representative older adults from 17 European countries, we found that approximately $30 \%$ of Europeans older than 65 years may have LLD, as suggested by higher scores on a common depression symptoms scale. The rate of LLD was highest in Southern Europe and CEE and lowest in Scandinavia. Depression was associated strongest with somatic comorbidities and physical and cognitive functioning. We observed a large gap in MHS use for LLD that reached almost $80 \%$.

Similar regional differences, pointing towards the highest burden of LLD in CEE and Southern Europe, were observed in the European Social Study [3], COMPARE study [4] and Generations and Gender Survey [5]. However, the European MentDis_ICF65+ study suggested a lower prevalence of major depressive episode in older adults residing in Southern Europe, when compared to their counterparts from Western Europe [1]. On the contrary, our findings are in accord with global literature reporting higher rates of depression in countries with poorer living conditions, lower welfare provision and higher income inequality [31,32]. It can be speculated that richer and stronger welfare states may reduce the burden of LLD by supporting older people to be independent and providing social and public services.

Although we observed some small gender and regional differences in the associations of LLD to various factors, the

Table 1

Differences between participants with and without depression $(n=28796)$.

\begin{tabular}{|c|c|c|c|}
\hline & $\begin{array}{l}\text { Depression } \\
(\mathrm{n}=7645)\end{array}$ & $\begin{array}{l}\text { No depression } \\
(\mathrm{n}=21151)\end{array}$ & $\mathrm{p}$ value \\
\hline \multicolumn{4}{|l|}{ Sociodemographic characteristics } \\
\hline Age, median (IQR) & $74(11)$ & $72(10)$ & $<0.001$ \\
\hline Women, $\mathrm{n}(\%)$ & $5113(67)$ & $10237(48)$ & $<0.001$ \\
\hline Years of education, mean $\pm S D$ & $9.5 \pm 4.3$ & $10.7 \pm 4.4$ & $<0.001$ \\
\hline Rural residence, $\mathrm{n}(\%)$ & $2570(34)$ & $6949(33)$ & 0.23 \\
\hline Immigration, $\mathrm{n}(\%)$ & $88(1)$ & $183(1)$ & 0.03 \\
\hline Currently not working, n (\%) & $7478(98)$ & $20288(96)$ & $<0.001$ \\
\hline Lowest decile of household income, $\mathrm{n}(\%)$ & $1144(15)$ & $1735(8)$ & $<0.001$ \\
\hline \multicolumn{4}{|l|}{ Social characteristics } \\
\hline Family status: alone, n (\%) & $2886(38)$ & $6018(29)$ & $<0.001$ \\
\hline Children: 2 and more, $\mathrm{n}(\%)$ & $5493(72)$ & $15608(74)$ & 0.001 \\
\hline Grandchildren: 3 and more, $\mathrm{n}(\%)$ & $4283(56)$ & $11383(54)$ & 0.001 \\
\hline Persons with daily contact, median (IQR) & $1(1)$ & $1(1)$ & 0.9 \\
\hline \multicolumn{4}{|l|}{ Comorbidities } \\
\hline Cardiovascular disease, n (\%) & $6165(81)$ & $14962(71)$ & $<0.001$ \\
\hline Cancer, n (\%) & $535(7)$ & $953(5)$ & $<0.001$ \\
\hline Cognitive impairment, n (\%) & $3279(43)$ & $4995(24)$ & $<0.001$ \\
\hline Number of chronic diseases: 2 and more, $\mathrm{n}(\%)$ & $5610(73)$ & $10943(52)$ & $<0.001$ \\
\hline Troubled by pain, $\mathrm{n}(\%)$ & $5224(68)$ & $8473(40)$ & $<0.001$ \\
\hline \multicolumn{4}{|l|}{ General health-related factors } \\
\hline Physical inactivity, $\mathrm{n}(\%)$ & $1613(21)$ & $1488(7)$ & $<0.001$ \\
\hline Obesity, n (\%) & $2188(29)$ & $4842(23)$ & $<0.001$ \\
\hline IADL: 4 and more limitations, $\mathrm{n}(\%)$ & $726(10)$ & $395(2)$ & $<0.001$ \\
\hline Maximal grip strength, mean $\pm S D$ & $26.8 \pm 10.1$ & $32.8 \pm 10.8$ & $<0.001$ \\
\hline Never used a computer, $\mathrm{n}(\%)$ & $4304(56)$ & $7629(36)$ & $<0.001$ \\
\hline Smoking, $\mathrm{n}(\%)$ & $2868(38)$ & $9373(44)$ & $<0.001$ \\
\hline Alcohol, n (\%) & $4275(56)$ & $8711(41)$ & $<0.001$ \\
\hline
\end{tabular}

IQR, interquartile range; SD, standard deviation; IADL, instrumental activities of daily living limitations. 
Table 2

The 5 most important factors associated with depression.

\begin{tabular}{|c|c|c|c|c|}
\hline Sample & Rank & Covariate & OR $(95 \% \mathrm{CI})$ & Explained variance (\%) \\
\hline All & 1 & Number of chronic diseases & $1.25(1.22 ; 1.27)$ & 19 \\
\hline \multirow{4}{*}{$(n=28796)$} & 2 & Pain & $1.97(1.85 ; 2.09)$ & 19 \\
\hline & 3 & IADL & $1.22(1.19 ; 1.25)$ & 14 \\
\hline & 4 & Grip strength & $0.98(0.97 ; 0.98)$ & 13 \\
\hline & 5 & Cognitive impairment & $1.59(1.49 ; 1.70)$ & 8 \\
\hline \multirow{5}{*}{$\begin{array}{l}\text { Women } \\
\qquad(\mathrm{n}=15350)\end{array}$} & 1 & Number of chronic diseases & $1.24(1.21 ; 1.28)$ & 22 \\
\hline & 2 & Pain & $1.97(1.82 ; 2.13)$ & 21 \\
\hline & 3 & IADL & $1.21(1.17 ; 1.25)$ & 15 \\
\hline & 4 & Cognitive impairment & $1.59(1.46 ; 1.74)$ & 10 \\
\hline & 5 & Grip strength & $0.97(0.96 ; 0.98)$ & 10 \\
\hline \multirow{5}{*}{$\begin{array}{l}\text { Men } \\
\qquad(n=13446)\end{array}$} & 1 & Number of chronic diseases & $1.25(1.21 ; 1.29)$ & 19 \\
\hline & 2 & Pain & $1.96(1.77 ; 2.16)$ & 19 \\
\hline & 3 & IADL & $1.24(1.19 ; 1.29)$ & 18 \\
\hline & 4 & Physical inactivity & $1.87(1.61 ; 2.16)$ & 12 \\
\hline & 5 & Cognitive impairment & $1.57(1.41 ; 1.75)$ & 9 \\
\hline \multirow[t]{5}{*}{ Western Europe ( $n=9940$ ) } & 1 & Pain & $2.11(1.90 ; 2.34)$ & 24 \\
\hline & 2 & Number of chronic diseases & $1.25(1.20 ; 1.30)$ & 21 \\
\hline & 3 & IADL & $1.20(1.14 ; 1.26)$ & 13 \\
\hline & 4 & Grip strength & $0.98(0.98 ; 0.99)$ & 12 \\
\hline & 5 & Female gender & $1.45(1.24 ; 1.69)$ & 8 \\
\hline \multirow[t]{5}{*}{ Southern Europe ( $n=7$ 022) } & 1 & IADL & $1.38(1.30 ; 1.47)$ & 20 \\
\hline & 2 & Number of chronic diseases & $1.24(1.18 ; 1.29)$ & 18 \\
\hline & 3 & Pain & $1.73(1.53 ; 1.95)$ & 13 \\
\hline & 4 & Grip strength & $0.98(0.98 ; 0.99)$ & 11 \\
\hline & 5 & Cognitive impairment & $1.56(1.38 ; 1.76)$ & 9 \\
\hline \multirow{5}{*}{$\begin{array}{l}\text { Central and Eastern Europe } \\
\qquad(\mathrm{n}=7845)\end{array}$} & 1 & Number of chronic diseases & $1.26(1.21 ; 1.31)$ & 19 \\
\hline & 2 & Pain & $2.00(1.78 ; 2.25)$ & 18 \\
\hline & 3 & Grip strength & $0.97(0.97 ; 0.98)$ & 15 \\
\hline & 4 & IADL & $1.20(1.15 ; 1.25)$ & 14 \\
\hline & 5 & Cognitive impairment & $1.63(1.44 ; 1.85)$ & 8 \\
\hline \multirow[t]{5}{*}{ Scandinavia ( $n=3$ 989) } & 1 & Grip of strength & $0.97(0.96 ; 0.99)$ & 19 \\
\hline & 2 & Pain & $1.86(1.53 ; 2.26)$ & 18 \\
\hline & 3 & Number of chronic diseases & $1.20(1.11 ; 1.29)$ & 15 \\
\hline & 4 & IADL & $1.19(1.09 ; 1.31)$ & 13 \\
\hline & 5 & Physical inactivity & $2.26(1.62 ; 3.16)$ & 13 \\
\hline
\end{tabular}

IADL, instrumental activities of daily living; OR, odds ratio; $\mathrm{CI}$, confidence interval.

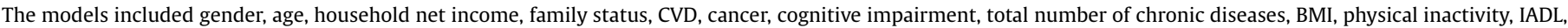
pain, grip strength and computer use.

dominance analysis demonstrated that the most important factors that explain the variation in the prevalence of depression are similar for men and women as well as individuals residing in different European regions. As opposed to previous studies that emphasized the effect of social and family factors as well as unhealthy behaviours in the development of $\operatorname{LLD}[33,34]$, we show that the most important factors that explained the highest proportion of variation in LLD were related to somatic health and physical and cognitive functioning. This is in line with a large prospective cohort study showing that physical and functional limitation is the largest contributor to the risk of LLD [35] and a recent meta-analysis suggesting a high correlation between physical multi-morbidity and depression [36].

The $79 \%$ gap in MHS use observed in this study suggests that the disparity in the service utilization for LLD is much higher than that reported for the global population (ages 15+) with depression, which is estimated to be $56 \%$ [27]. The number of somatic disorders was positively associated with utilization of MHS, indicating that persons with comorbid diseases have frequent contact with health services, where depression may get diagnosed and treated. On the contrary, LLD may go unnoticed in adults who do not visit physicians due to somatic disorders. We propose several changes for decreasing the burden of LLD and closing the gap in MHS use. First, this gap could be addressed by promoting help-seeking behaviour in older adults. Since perception of need for help is impaired by a lack of knowledge, prejudice, selfstigmatization and discrimination, even by medical staff [37,38], we propose that physicians adopt highly professional behavior including non-stigmatizing approaches to care. With ageism being highly prevalent, socially accepted, usually unchallenged [39], and standing as a barrier in seeking help through MHS [40], stigma reduction initiatives should be implemented in all levels of medical education given the current demographic transition. In addition, portraying professional mental health treatment as extending beyond biomedical problems could contribute to closing the gap in MHS utilization [38].

Because primary care is the preferred care setting for older adults [41], understanding of LLD by general practitioners needs to be improved and its detection should be increased, using evidencebased guidelines [42]. We suggest that general practitioners look for symptoms of depression in particular in individuals that have several chronic somatic conditions and are limited in functioning, with instruments specific for their age. There are several screening tools validated in a geriatric and primary care setting: the Geriatric Depression Scale [43], Center for Epidemiologic Studies Depression Scale [44], Patient Health Questionnaire 2 and 9 [45-47] and The Hospital Anxiety and Depression Scale [48].

Prevention is needed in individuals who are at risk of depression or are already mildly symptomatic [41]. The literature reports effective interventions for prevention of LLD that are feasible in primary-care setting [49]. For example, a pragmatic randomized trial identified that a stepped-care program targeting older adults with mild depressive symptomatology reduced the incidence of depression, when compared to usual care. This intervention consisted of tiers of watchful waiting, cognitive behaviour therapy-based bibliotherapy, cognitive behaviour therapy-based problem solving and pharmacological medication, if required [49]. Further, there are effective primary care-based 
Table 3

Characteristics of individuals with depression by utilization of mental health services ( $n=7645$ ).

\begin{tabular}{|c|c|c|c|}
\hline & $\begin{array}{l}\text { Service users } \\
(\mathrm{n}=1603)\end{array}$ & Service non-users $(n=6042)$ & $\mathrm{p}$ value \\
\hline \multicolumn{4}{|l|}{ Sociodemographic characteristics } \\
\hline Age, median (IQR) & $74(10)$ & $75(11)$ & 0.001 \\
\hline Women, n (\%) & $1207(75)$ & $3906(65)$ & $<0.001$ \\
\hline Years of education, mean $\pm S D$ & $9.1 \pm 4.4$ & $9.6 \pm 4.2$ & $<0.001$ \\
\hline Rural residence, $\mathrm{n}(\%)$ & $549(34)$ & $2021(33)$ & 0.55 \\
\hline Immigration, $\mathrm{n}(\%)$ & $25(2)$ & $63(1)$ & 0.09 \\
\hline Currently working, n (\%) & $23(1)$ & $144(2)$ & 0.02 \\
\hline Lowest decile of yearly household income, $\mathrm{n}(\%)$ & $242(15)$ & $902(15)$ & 0.87 \\
\hline \multicolumn{4}{|l|}{ Social characteristics } \\
\hline Family status: alone, n (\%) & $643(40)$ & $2243(37)$ & 0.03 \\
\hline Children: 2 and more, $\mathrm{n}(\%)$ & $1118(70)$ & $4375(72)$ & 0.04 \\
\hline Grandchildren: 3 and more, $\mathrm{n}(\%)$ & $893(56)$ & $3389(56)$ & 0.78 \\
\hline Persons with daily contact, median (IQR) & $1(1)$ & $1(1)$ & 0.93 \\
\hline \multicolumn{4}{|l|}{ Comorbidities } \\
\hline Cardiovascular disease, n (\%) & $1311(82)$ & $4854(80)$ & 0.19 \\
\hline Cancer, n (\%) & $128(8)$ & $407(7)$ & 0.08 \\
\hline Cognitive impairment, $\mathrm{n}(\%)$ & $763(48)$ & $2516(42)$ & $<0.001$ \\
\hline Number of chronic diseases: 2 and more, $\mathrm{n}(\%)$ & $1404(88)$ & $4206(70)$ & $<0.001$ \\
\hline Troubled by pain, n (\%) & $1217(76)$ & $4007(66)$ & $<0.001$ \\
\hline \multicolumn{4}{|l|}{ General health-related factors } \\
\hline Physical inactivity, n (\%) & $408(26)$ & $1205(20)$ & $<0.001$ \\
\hline Obesity, n (\%) & $494(31)$ & $1694(28)$ & 0.03 \\
\hline IADL: 4 and more limitations, $\mathrm{n}(\%)$ & $248(16)$ & $478(8)$ & $<0.001$ \\
\hline Maximal grip strength, mean $\pm S D$ & $24.7 \pm 9.8$ & $27.3 \pm 10.0$ & $<0.001$ \\
\hline Never used a computer, n (\%) & $944(59)$ & $3360(56)$ & 0.02 \\
\hline Smoking, $\mathrm{n}(\%)$ & $602(38)$ & $2266(38)$ & 0.97 \\
\hline Alcohol, n (\%) & $612(38)$ & $2758(46)$ & $<0.001$ \\
\hline
\end{tabular}

IQR, interquartile range; SD, standard deviation; IADL, instrumental activities of daily living.

Table 4

Associations of individual characteristics with utilization of mental health services in persons with depression $(n=7645)$.

\begin{tabular}{ll}
\hline & OR $(95 \% \mathrm{CI})$ \\
\hline Age & $0.96(0.95 ; 0.97)^{* *}$ \\
Women & $1.51(1.26 ; 1.80)^{* *}$ \\
Years of education & $0.99(0.98 ; 1.00)$ \\
Cognitive impairment & $1.20(1.05 ; 1.38)^{*}$ \\
Number of chronic diseases & $1.44(1.39 ; 1.49)^{* *}$ \\
Troubled by pain & $0.96(0.83 ; 1.10)$ \\
Physical inactivity & $0.94(0.81 ; 1.10)$ \\
BMI & $0.98(0.97 ; 0.99)^{*}$ \\
IADL & $1.12(1.08 ; 1.16)^{* *}$ \\
Maximal grip strength & $0.99(0.99 ; 1.00)$ \\
Alcohol & $0.98(0.87 ; 1.11)$ \\
\hline
\end{tabular}

$\overline{\mathrm{OR} \text {, odds ratio; } \mathrm{CI} \text {, confidence interval; BMI, body mass index; IADL, instrumental }}$ activities of daily living.

${ }^{*} \mathrm{p}<0.05 ;{ }^{* *} \mathrm{p}<0.001$.

interventions for the treatment of LLD [50]. For example, a randomized controlled trial concluded that a collaborative care management program providing access to a depression care manager who offered education, personally tailored pharmacotherapy, psychotherapy and a course in problem solving was significantly more effective at depression treatment compared with usual care [50].

This study is strengthened by a population-based design and a large sample size, including individuals from CEE that have been underrepresented in previous studies [26] and can be generalized to adults aged 65 years or older residing in Europe. Several limitations should be noted: There are potential residual confounders, such as genetics or past sociodemographic and health related factors. Furthermore, the indicator of MHS utilization was constructed based on self-reported information, which may not be accurate due to several reasons, such as cognitive impairment or participants' lack of awareness of taking antidepressants. This can bias our findings and overestimate the gap of MHS utilization found in the present study. In addition, reporting of some factors, such as pain or IADL may have been influenced by depressed mood, thus differentially misclassified, potentially overestimating their association with depression.

\section{Availability of data and materials}

Access to the SHARE data is provided free of charge on the basis of a release policy that gives quick and convenient access to all scientific users world-wide after individual registration. All details about the application and registration process can be found on this website: http://www.share-project.org. The study protocol and syntax of the statistical analysis will be shared upon request from the corresponding author of this study.

\section{Acknowledgements}

This paper uses data from SHARE Wave 6 (DOIs: 10.6103/SHARE. w6.600), see Börsch-Supan et al. (2013) for methodological details ${ }^{1}$. The SHARE data collection has been primarily funded by the European Commission through FP5 (QLK6-CT-2001-00360), FP6 (SHARE-I3: RII-CT-2006-062193, COMPARE: CIT5-CT-2005-028857, SHARELIFE: CIT4-CT-2006-028812) and FP7 (SHARE-PREP: №211909, SHARE-LEAP: $\mathrm{N}^{\circ} 227822$, SHARE M4: №261982). Additional funding from the German Ministry of Education and Research, the Max Planck Society for the Advancement of Science, the U.S. National Institute on Aging (U01_AG09740-13S2, P01_AG005842, P01_AG08291, P30_AG12815, R21_AG025169, Y1-AG-4553-01, IAG_BSR06-11, OGHA_04-064, HHSN271201300071C) and from various national funding sources is gratefully acknowledged (see www.share-project.org). The authors were supported by the Sustainability for the National Institute of Mental Health" (grant L01611), with a financial support from the Ministry of Education, Youth and Sports of the Czech Republic. 


\section{Appendix A. Supplementary data}

Supplementary material related to this article can be found, in the online version, at doi:https://doi.org/10.1016/j.eurpsy.2018.12.002.

\section{References}

[1] Andreas S, Schulz H, Volkert J, Dehoust M, Sehner S, Suling A, et al. Prevalence of mental disorders in elderly people: the European MentDis_ICF65+ study. The British journal of psychiatry. J Mental Sci 2017;210:125-31.

[2] Kohler CA, Evangelou E, Stubbs B, Solmi M, Veronese N, Belbasis L, et al Mapping risk factors for depression across the lifespan: an umbrella review of evidence from meta-analyses and mendelian randomization studies. J Psychiatr Res 2018;103:189-207.

[3] Van de Velde S, Bracke P, Levecque K. Gender differences in depression in 23 European countries. Cross-national variation in the gender gap in depression. Soc Sci Med 2010;71:305-13.

[4] Kok R, Avendano M, d'Uva TB, Mackenbach J. Can reporting heterogeneity explain differences in depressive symptoms across Europe? Soc Indic Res 2012;105:191-210.

[5] Hansen T, Slagsvold B. The East-West divide in late-life depression in Europe: results from the generations and gender survey. Scand Psychol 2017;4:.

[6] Kessler RC, Bromet EJ. The epidemiology of depression across cultures. Annu Rev Public Health 2013;34:119-38.

[7] Bøe T, Balaj M, Eikemo TA, McNamara CL, Solheim EF. Financial difficulties in childhood and adult depression in Europe. Eur J Public Health. 2017;27:96-101.

[8] Copeland JR, Beekman AT, Braam AW, Dewey ME, Delespaul P, Fuhrer R, et al. Depression among older people in Europe: the EURODEP studies. World Psychiatry 2004;3:45.

[9] Castro-Costa E, Dewey M, Stewart R, Banerjee S, Huppert F, Mendonca-Lima C, et al. Prevalence of depressive symptoms and syndromes in later life in ten European countries: the SHARE study. Brit J Psychiatry 2007;191:393-401.

[10] Kessler RC, Birnbaum H, Bromet E, Hwang I, Sampson N, Shahly V. Age differences in major depression: results from the national comorbidity survey replication (NCS-R). Psychol Med 2010;40:225-37.

[11] Snowdon J. Is depression more prevalent in old age? Aust New Zeal JPsychiatry. 2001;35:782-7.

[12] Gertner AK, Domino ME, Dow WH. Risk factors for late-life depression and correlates of antidepressant use in Costa Rica: results from a nationallyrepresentative longitudinal survey of older adults. J Affect Disord 2017;208:338-44.

[13] Tsai FJ, Motamed S, Rougemont A. The protective effect of taking care of grandchildren on elders' mental health? Associations between changing patterns of intergenerational exchanges and the reduction of elders' loneliness and depression between 1993 and 2007 in Taiwan. BMC Public Health 2013;13:567.

[14] Enache D, Fereshtehnejad SM, Kareholt I, Cermakova P, Garcia-Ptacek S, Johnell K, et al. Antidepressants and mortality risk in a dementia cohort: data from SveDem, the Swedish dementia registry. Acta Psychiatrica Scand 2016;134:430-40.

[15] Correll CU, Solmi M, Veronese N, Bortolato B, Rosson S, Santonastaso P, et al. Prevalence, incidence and mortality from cardiovascular disease in patients with pooled and specific severe mental illness: a large-scale meta-analysis of 3,211,768 patients and 113,383,368 controls. World Psychiatry 2017;16:16380.

[16] Molero P, Ángel Martinez-Gonzalez M, Ruiz-Canela M, Lahortiga F, et al. Cardiovascular risk and incidence of depression in young and older adults: evidence from the SUN cohort study. World Psychiatry 2017;16:111.

[17] Miloyan B, Fried E. A reassessment of the relationship between depression and all-cause mortality in 3,604,005 participants from 293 studies. World Psychiatry 2017;16:219-20.

[18] Unützer J, Katon W, Callahan CM, et al. Collaborative care management of latelife depression in the primary care setting: a randomized controlled trial. JAMA. 2002;288:2836-45.

[19] Reynolds CFR, Patel V. Screening for depression: the global mental health context. World Psychiatry 2017;16:316-7.

[20] Gregg JJ, Fiske A, Gatz M. Physicians' detection of late-life depression: the roles of dysphoria and cognitive impairment. Aging Mental Health 2013;17:1030-6.

[21] Goldberg D. The detection and treatment of depression in the physically ill. World Psychiatry 2010;9:16-20.

[22] Mackenzie CS, Pagura J, Sareen J. Correlates of perceived need for and use of mental health services by older adults in the collaborative psychiatric epidemiology surveys. Am J Geriatr Psychiatry 2010;18:1103-15.
[23] Angermeyer MC, van der Auwera S, Carta MG, Schomerus G. Public attitudes towards psychiatry and psychiatric treatment at the beginning of the 21 st century: a systematic review and meta-analysis of population surveys. World Psychiatry 2017;16:50-61.

[24] Börsch-Supan A, Brandt M, Hunkler C, Kneip T, Korbmacher J, Malter F, et al. Data resource profile: the survey of health, ageing and retirement in Europe (SHARE). Int J Epidemiol 2013;42:992-1001.

[25] Prince MJ, Reischies F, Beekman A, Fuhrer R, Jonker C, Kivela S-L, et al. Development of the EURO-D scale-a European, Union initiative to compare symptoms of depression in 14 European centres. Brit J Psychiatry 1999; 174:330-8.

[26] Winkler P, Formanek T, Mlada K, Cermakova P. The CZEch mental health study (CZEMS): study rationale, design, and methods. Int J Methods Psychiatric Res 2018;27:e1728.

[27] Kohn R, Saxena S, Levav I, Saraceno B. The treatment gap in mental health care. Bull World health Org 2004;82:858-66.

[28] Cermakova P, Formanek T, Kagstrom A, Winkler P. Socioeconomic position in childhood and cognitive aging in Europe. Neurology 2018;91:e1602-10.

[29] Deville J-C, Särndal C-E. Calibration estimators in survey sampling. J Am Statis Assoc 1992;87:376-82.

[30] Azen R, Traxel N. Using dominance analysis to determine predictor importance in logistic regression. J Educ Behav Statis 2009;34:319-47.

[31] Patel V, Burns JK, Dhingra M, Tarver L, Kohrt BA, Lund C. Income inequality and depression: a systematic review and meta-analysis of the association and a scoping review of mechanisms. World Psychiatry 2018;17:76-89.

[32] Kessler RC, Bromet EJ. The epidemiology of depression across cultures. Ann Rev Public Health 2013;34:119-38.

[33] Seeman TE. Health promoting effects of friends and family on health outcomes in older adults. Am J Health Promot 2000;14:362-70.

[34] Devanand D. Comorbid psychiatric disorders in late life depression. Biol Psychiatry 2002;52:236-42.

[35] Chang S-C, Pan A, Kawachi I, Okereke OI. Risk factors for late-life depression: a prospective cohort study among older women. Prev Med 2016;91:144-51.

[36] Stubbs B, Vancampfort D, Veronese N, Kahl KG, Mitchell AJ, Lin PY, et al. Depression and physical health multimorbidity: primary data and countrywide meta-analysis of population data from 190593 people across 43 low- and middle-income countries. Psychol Med. 2017;47:2107-17.

[37] Schomerus G, Stolzenburg S, Freitag S, Speerforck S, Janowitz D, Evans-Lacko S, et al. Stigma as a barrier to recognizing personal mental illness and seeking help: a prospective study among untreated persons with mental illness. Eur Arch Psychiatry Clin Neurosci. 2018.

[38] Stolzenburg S, Freitag S, Evans-Lacko S, Speerforck S, Schmidt S, Schomerus G. Individuals with currently untreated mental illness: causal beliefs and readiness to seek help. Epidemiol Psychiatric Sci 2018;1-12.

[39] Cuddy AJ, Norton MI, Fiske ST. This old stereotype: the pervasiveness and persistence of the elderly stereotype. I Social Issues 2005;61:267-85.

[40] Robb C, Chen H, Haley WE. Ageism in mental health and health care: a critical review. J Clin Geropsychol 2002;8:1-12.

[41] Hall CA, Reynolds-Iii CF. Late-life depression in the primary care setting: challenges, collaborative care, and prevention. Maturitas 2014;79:147-52.

[42] Smith M, Haedtke C, Shibley D. Late-life depression detection. J Gerontol Nurs 2015;41:18-25.

[43] Mitchell AJ, Bird V, Rizzo M, Meader N. Diagnostic validity and added value of the geriatric depression scale for depression in primary care: a meta-analysis of GDS30 and GDS15. J Affect Disord 2010;125:10-7.

[44] Beekman AT, Deeg D, Van Limbeek J, Braam AW, De Vries M, Van Tilburg W. BRIEF COMMUNICATION.: Criterion validity of the center for epidemiologic studies depression scale (CES-D): results from a community-based sample of older subjects in the Netherlands. Psychol Med 1997;27:231-5.

[45] Manea L, Gilbody S, Hewitt C, North A, Plummer F, Richardson R, et al. Identifying depression with the PHQ-2: a diagnostic meta-analysis. J Affect Disord 2016;203:382-95.

[46] Arroll B, Goodyear-Smith F, Crengle S, Gunn J, Kerse N, Fishman T, et al. Validation of PHQ-2 and PHQ-9 to screen for major depression in the primary care population. Ann Fam Med 2010;8:348-53.

[47] Kroenke K, Spitzer RL, Williams JB. The PHQ-9: validity of a brief depression severity measure. J Gen Intern Med 2001;16:606-13.

[48] Zigmond AS, Snaith RP. The hospital anxiety and depression scale. Acta Psychiatr Scand 1983;67:361-70.

[49] van't Veer-Tazelaar PJ, van Marwijk HJ, van Oppen P, et al. Stepped-care prevention of anxiety and depression in late life: a randomized controlled trial. Arch Gen Psychiatry 2009;66:297-304.

[50] Unutzer J, Katon W, Callahan CM, Williams Jr. JW, Hunkeler E, Harpole L, et al. Collaborative care management of late-life depression in the primary care setting: a randomized controlled trial. Jama 2002;288:2836-45. 